\title{
Dynamic Assessment in Perspective: Demarcating Dynamic and Non-dynamic Boundaries
}

\author{
Mohammad Bavali \\ Department of English Language Teaching and Translation, Islamic Azad University, Shiraz Branch, Shiraz, Iran \\ Email: mohammadbavali_57@yahoo.com \\ Mortaza Yamini \\ Department of English Language Teaching and Translation, Islamic Azad University, Shiraz Branch, Shiraz, Iran \\ Email: myamini@rose.shirazu.ac.ir \\ Firooz Sadighi \\ Department of English Language Teaching and Translation, Islamic Azad University, Shiraz Branch, Shiraz, Iran \\ Email: firoozsadighi@yahoo.com
}

\begin{abstract}
Ever since the concept of dynamic assessment (also DA) was introduced into the literature on language pedagogy, it has received various interpretations in terms of its scope, meaning, purpose, and even its practical realization. This difference in interpretation, the raison d'être of DA, however, has resulted in a burgeoning variation in the number and types of procedures and practices employed in $L 2$ classrooms under DA programs, a fact which seems to have gone unnoticed by both the critics and advocates of DA approaches to $L 2$. The present article, therefore, tries to define DA within the very conceptual framework it was originally introduced and to sketch the theoretical and practical scopes which serve to realize that framework. To this end, this article provides an account of the basic tenets and principles underlying DA and also examines the degree to which each of the major approaches to DA have realized those basic principles in practice.
\end{abstract}

Index Terms - dynamic assessment, zone of proximal development, socio-cultural theory of learning, mediated learning experience, modifiability

\section{INTRODUCTION}

The turn of the century is marked with changes in the theoretical and practical orientations in educational settings including language pedagogy. Such changes, among other things, have provoked modifications in the classroom procedures in a systematic way. One of the most important reconsiderations (at least in theory) came about in reaction to classic assessment procedures which had dominated (and still keep on dominating) educational settings worldwide.

Until very recently, static psychometric assessment procedures and techniques were utilized as most reliable means of yielding valid results on specific abilities of learners, and the obtained measures were considered not only as an indication of the current status of the learners' abilities but as predictors of the learners' future courses of action. The problem lay in the fact that such interpretations were made on the basis of only one or two summative assessments (e.g. achievement tests) which, in practice, turned out to yield undependable results.

Through the introduction of new trends in the field of educational psychology, such as sociocultural theory of learning, zone of proximal development and structural cognitive modifiability (Feuerstein, Rand, \& Hoffman,1979; Feuerstein, Rand, Hoffman, \& Miller, 1980; Feuerstein, Rand, \& Rynders, 1988; Feuerstein, Falik, Rand, \& Feuerstein, 2003), a novel orientation towards assessment and instruction began to receive warm welcome from different disciplines, including applied linguistics, which ultimately led to a new approach to assessment and instruction known as dynamic assessment.

Unlike traditional psychometric approaches to assessment, DA capitalized on instruction during the assessment itself - it tapped into the pedagogical function of assessment in providing opportunities for learning to occur.

Moreover, while prediction had been traditionally thought to be a function peculiar to prognostic assessments, proponents of DA believed that one type of prediction - learners' future development - is something that any sound assessment should be able to make. This prognostic aspect of assessment, they argued, is not meaningful unless the learner's performance is mediated by a tutor-examiner. These basic tenets derived from the concept of the zone of proximal development introduced by the Russian psychologist Lev Vygotsky who insisted that any assessment must, among other things, include a specification of the degree to which the testee's performance is modifiable. The extent to 
which modifications can be made indicates the zone of proximal development or the person's potential learning capacity in future.

Despite this clarity in theory and practice, DA has been subject to distinct and sometimes even conflicting interpretations with, in some extreme cases, little if any correspondence to the original assumptions or principles. This study, therefore, has taken up the express objective of providing a working definition for dynamic assessment so that models proposed under DA elsewhere could be critically analyzed and evaluated. To this end, we first scrutinize the basic assumptions and principles underlying DA and then examine the existing approaches to DA against them. The degree to which each of those approaches conforms to the basic principles and conceptualizations of the theory is an index of the construct validity of that approach. This focus is largely motivated by the fact that there are a number of approaches to dynamic assessment which seem to be only superficially, and by no means theoretically, related to DA's assumptions and procedures (Sternberg \& Grigorenko, 2002); approaches which are indeed assessment techniques disguised as DA such as formative assessments or assessment procedures developed based on views rooted in Piaget's cognitive constructivism.

\section{DYNAMIC ASSESSMENT: PRINCIPLES AND ASSUMPTIONS}

\section{A. Zone of Proximal Development}

Dynamic assessments were developed as a means of realizing the concept of the zone of proximal development introduced by Vygotsky in his social constructivistic theory of learning. According to him, learners' performance level, their developmental scheme, is two-fold: their current level of development and their potential level of development or, in Vygotsky's (1962) words, the "zone of present development" and the "zone of proximal development" (ZPD), respectively. The former pertains to learners' existing ability to display a performance level without external assistance; the latter connotes the extent to which learners can move away from this existing performance level towards the one developed under guidance and assistance. ZPD, then, can be defined as "the distance between current developmental level achieved without assistance and the level of potential development ascertained through guidance" (Dorfler, Golke, \& Artlet, 2009, p.77).

\section{B. Dynamic Assessment: Definitions}

It is apparent that the key feature in the concept of ZPD is the amount of change in the performance of learners as a result of assistance received from more capable and informed individuals, the so-called mediators or tutor-examiners, who offer mediations, ranging from prompts and hints through prefabricated or spontaneous questions and explanations. The goal is to modify learners' performance level in order to enable the mediators not only to understand individual learners' current level of abilities but to predict (assess) their unassisted potential future abilities based on their present performance in assisted (instructed) completion task settings.

The question which arises immediately is whether these very assumptions have been incorporated into definitions given for DA, notwithstanding the inevitable differences in wordings.

Dorfler et al (2009) have defined DA as "one approach to gaining insight into the current level of competence as well as into how this competence can be influenced by specific educational interventions" (p. 77).

Lussier and Swanson (2005) define dynamic assessment as a "procedure that attempts to modify performance, via examiners' assistance, in an effort to understand learning potential" (p. 66).

Lidz (1991) defines dynamic assessment as "an approach that follows a test-intervene-retest format, and that focuses on learner modifiability and on producing suggestions for interventions that appear successful in facilitating improved learner performance" (p. 6).

Poehner (2008) has provided the following definition: "active collaboration with individuals simultaneously reveals the full range of their abilities and promotes their development. In educational contexts, this means that assessment understanding learners' abilities - and instruction - supporting learner development - are a dialectically integrated activity. This pedagogical approach has come to be known as Dynamic Assessment" (p. 2).

Adopting the common features of these definitions, dynamic assessment could be viewed as a complex of procedures around the task of modifying learners' performances via tutor-examiners' assistance in an effort to yield information as to the potential development of the testees in future.

However, this concept of modifiability seems to have been conceptualized and defined in different ways in the definitions given above, where the means of making modifications (collaboration as opposed to intervention) and assessing them (pretest-posttest difference as opposed to within-test-measures) are quite different. Such differences have given rise to distinct approaches to DA since its inception in the early 1970s and, at the same time, to a controversy over the legitimacy of such approaches and even over the validity of the construct itself.

Meanwhile, in some educational and research settings formative assessments and Piaget's cognitive constructivist views about assessment have been wrongly equated with and/or interpreted as dynamic assessments.

Since the concept of modifiability has proven problematic at the outset, the next section tries to capture the essence of the concept by explicating it within the conceptual framework within which it was originally introduced.

C. Modifiability: Stability of Change and Learners' Learning Potential 
Modifiability is viewed in DA as the main feature characterizing a learner's zone of proximal development (Kozulin \& Garb, 2002; Lidz \& Elliott, 2000). As mentioned earlier, DA embraces the assumption that any assessment must include a specification of the degree to which the testee's performance is modifiable. The extent of modifiability is an indicator of the ZPD or the person's potential learning capacity in future. The important point about modifiability, however, is its stability. Stability of the modified behavior is an essential factor in determining the future development of the learners. This point has been eloquently made by Luria where, dynamic assessment, according to her "argues that a full picture requires two additional bits of information: the person's performance with assistance from someone else and the extent to which the person can benefit from this assistance not only in completing the same task or test, but in transferring this mediated performance to different tasks or tests" (cited in Poehner and Lantolf, 2005, p. 234).

It follows that, with adequate stability in the modified performance, parts of the learning process can actually be completed within the zone of proximal (i.e. emerging) development; that is, what learners can do today with help and resources, they can most probably do in future on their own. Within the ZPD, then, the goal is to establish the amount of change that can be induced during interactions with the examiner during the assessment process; that is why DA is sometimes referred to as "assessment by teaching" as opposed to "assessment while teaching" (Newman, Griffin, \& Cole, 1989). This interpretation captures the essence of the express goal of DA: "to unify assessment and instruction into a single activity the goal of which is learner development" (Poehner \& Lantolf, 2005, p. 254).

However, as mentioned earlier, the ways in which modifiability has been conceptualized within ZPD, along with a number of other factors, has led to distinct interpretations or different approaches to DA. The remainder of this paper represents an account of these distinct conceptualizations and examines them against the principles discussed above. Finally a definition for DA is proposed which will hopefully conceptualize the construct and its components in harmony with the principles specified earlier here in this paper.

\section{DA: INTERACTIONIST OR INTERVENTIONIST?}

The quantitative interpretation of modifiability in ZPD capitalizes on the psychometric notion of 'difference score': the measured difference between what testees could do on their own and what they could do with help and assistance. In this kind of interpretation, typical of test-teach-retest designs, the zone of learners' proximal development is quantitatively computed as the difference between the learners' performances before and after treatment, that is, the difference, in number, between the scores obtained before remedial instruction (instructor's intervention) and those obtained after it as a result of exerted modifications. That is why this approach is called a quantitative interventionist approach or simply an interventionist approach.

Once compared against the definition given above for DA, however, quantitative interventionist approaches turn out to lack construct validity in that they do not conform to the basic assumptions underlying dynamic assessments. In other words, interventionist approaches do not practically realize what they purportedly claim to be the beating heart of DA in general and ZPD in particular: to yield information as to the potential development of the testees in future. What they supply is neither the result of assistance under assessment conditions, as the two take place quite independently, nor the consequence of assessing the ability to transfer the mediated performance beyond the immediate task to others. In other words, what they yield is again no more than the zone of the learners' present development, the information which is already obtainable without DA. The main reason for these flaws may lie in the means and the methods of obtaining information as they are all psychometric in nature, demanding independent means of instruction and assessment.

In test-teach-retest, a common interventionist design, for example, the tutor-examiner's assistance is not provided at the time of assessment but when learners are receiving instructions in typical teacher-centered classroom settings. Also in another interventionist design, graduated prompting, though assistance is in synchrony with assessment, it is not aimed at any modifications in learner performance meaning that mediation actually will not result in any changes as the time allocated to both mediation and prompting is not long enough to allow for any changes; by the same token, assessing a learners' ability in transferring an intact behavior is but misleading and fruitless. Moreover, the immediate needs of learners are not revealed as they have almost no roles in the process of constructing the reality, where learners are all seen as comparable against a pre-established menu of hints and rank-scale labels in a passive fashion.

A qualitative interactionist DA, on the other hand, puts a qualitative interpretation on ZPD; instead of measuring or rating (on scales) existing learning abilities of the examinees, typical of interventionists, interactionists conceive of DA as "a means of gaining insight into the kinds of psychological processes that the [learner] might be capable of displaying in the next or proximal phase of development and a means of identifying the kinds of instruction, or assistance that will be required if the [learner] is to realize these potentials" (Minick,1987, p. 127).

Feuerstein et al $(1988 ; 2003)$ have introduced an interactionist model which is based on two interrelated hypotheses. The first hypothesis, known as the theory of structural cognitive modifiability, strongly supports the position held by Vygotsky that our cognitive abilities are constructed by sociocultural interaction and instruction. This permeability to external, but relevant, phenomena results in variant sociocognitive structures "depending on the presence and the quality of appropriate forms of interaction and instruction" (Feuerstein et al., 1988, p. 5). This last assertion about interaction and instruction brings up the second hypothesis, the so-called mediated learning experience (MLE) according to which the examinee's performance is mediated by an adult mediator who provides the examinees with instructions needed to successfully accomplish the administered problem solving tasks and who is to record afterwards 
the kinds of instruction, assistance and modifications required for the examinee's successful transfer of assisted (or mediated) learning experience - the use of relevant psychological processes - into other unassisted contexts of use, that is, the desired structural cognitive change. Feuerstein defines MLE as "a process through which environmental stimuli do not impact directly on the organism but are filtered through some other person" (2003, p. 240).

Of the MLE components defined so far (Feuerstein et al, 1988, 1980, \& 1979) three of them are directly relevant to second language learning in educational settings: intentionality, reciprocity and transcendence.

Intentionality, the most important of the three, is the component which best materializes the basic assumption underlying ZPD, namely the tutor-examiner's deliberate mediation of the material to be learned by the learners. As the definition speaks for itself, it is used to stand in total contrast to occasional, incidental mediation typical of classic instructor-learner relationships where instructors' interventions mostly take place in a haphazard unsystematic manner. Such mediation, if any, would hardly result in any development; nor would it lead to any dependable prediction about the examinees' potential (future) development which, as mentioned earlier, is the express goal of ZPD.

The second component, Reciprocity, underscores the significance of a mutual involvement of both the learner and the instructor in the construction of the intended cognitive structure. This interaction is, again, inevitable, if, according to ZPD, a fully-fledged transferable learning (Transcendence; the third component) is to take place. Reciprocity serves to realize the premises asserted within the other two components so that its absence will culminate in a distortion of the whole picture as it fails to take account of the ZPD. This point has almost gone unnoticed by the proponents of interventionist approaches to DA as the tutor-examiner is already equipped with pre-established sequences of questions and cues during the teaching phase where the learner is merely considered as a passive recipient of the prescriptive mediations. Interactionists (e.g. Feuerstein et al, 1979), on the other hand, are more flexible and interactive offering different types of mediation depending on specific needs revealed by the student during the assessment, one more reason for lending credence to interactionist approaches.

Transcendence, as the third component, materializes the ultimate goal of the mediated learning, namely that of transferring what a learner can do with assistance now, beyond the immediate task and context to other tasks and contexts of use in as varied orders as possible to meet the demands of the new conditions. When this is attained cognitive development can be claimed to have occurred as well.

\section{DA: SOCIAL CONSTRUCTIVISM OR COGNITIVE CONSTRUCTIVISM?}

The principles and procedures in DA rely heavily on the theoretical assumptions highlighted in Vygotsky's zone of proximal development. What is unique about Vygotsky's theory is its adherence to developmental psychology, on the one hand, and sociocultural theories of learning, on the other, in a dialectic fashion. This has also gone unnoticed in a number of interpretations, leading to models and approaches that share little, if any, with assumptions and realizations highlighted earlier in ZPD-based DA programs. The problem then lies in the deviations from Vygotsky's theory as a result of imposing upon it interpretations which indeed do not conform to its original theoretical and practical make up. In some treatments of DA (e.g. Yunian, \& Ness, 1999; Budoff, 1987), it has been wrongly equated with the concept of ongoing evaluation, after Piaget's underscoring a step-wise incremental evaluation of developmental stages in learners as the most legitimate gauge of their potentialities. While such interpretations could bear practical pedagogic implications in L2 settings, they are, however, drawn more from Piagetian purely cognitive developmental psychology than Vygotskian sociocognitive developmental psychology, where only the latter captures the essence of the heart of DA. Hence, a brief account of the two standpoints follows so that lines of demarcation between the two theoretical positions could be adequately sketched.

Both Piaget and Vygotsky were developmental psychologists and shared a lot in their views about learning and human cognitive system in general. They, however, differed in the weight they attached to environmental factors and the role they assigned to other interlocutors in the process of cognitive development and hence learning of individual learners. While Piaget conceived of linguistic development as a phenomenon which depends on and originates from cognitive development, Vygotsky believed that "Social interaction, through language, is a prerequisite to cognitive development" (Brown, 2007, p. 43).

Piaget claimed that language acquisition is subordinate to concept acquisition and that this acquisition of concepts or knowledge about the world is based on an underlying cognitive structure which consists of a number of schemata (general potentialities to engage in a class of overt or covert actions) available at any given time to interact with the physical environment. To him, then, language learning is one among a number of aspects of the more general cognitive process of concept acquisition.

In Piaget's system the cognitive structure and its schemata result from biological maturation and cumulative experience, which are both in turn bound to the individual learners and are thus intrapersonal. In the first place, maturational processes not only account for the organism's [Piaget's own terminology] innate ability to interact with the environment, but also for the stage-wise increase in learning abilities. These schemata determine the organism's initial experiences and set bounds on their interactions with the environment, i.e., on what can be assimilated by the organism (Hergenhahn \& Olsen, 1993).

At different stages of life, an organism is able to respond to the environment according to its cognitive structure. However, the way an organism is able to interact with its environment changes over time. In other words, encounter 
with new environmental phenomena leads to a change in the number of schemata available to the organism in its cognitive structure. Hence a new process is called for to account for the organism's intellectual gap. This cognitive process is called accommodation which is the process by which the cognitive structure is modified.

The driving force behind this modification or intellectual growth, according to Piaget (cited in Hergenhahn \& Olsen, 1993), is a kind of innate tendency, within all organisms, to create a harmonious relationship (maximal adaptation or balance) between themselves and their environment. This innate tendency to organize one's experiences to assure optimal adaptation is called equilibrium or cognitive balance. Also, Piaget believed that learning (accommodation) depends on failure of previous knowledge to allow for assimilation of an experience. This gap or failure is what Piaget considered as an optimal condition for learning. In other words, optimal learning takes place if and only if the information or stimuli presented can be assimilated into the organism's present cognitive structure though at the same time it should be different enough to allow for a change in that structure. If schemata radically change through accommodation, resulting in a new mode of thinking, a stage is said to have formed.

Vygotsky shares the same views with Piaget as far as biological maturation, schemes, and the processes of assimilation and accommodation are concerned. They differ, however, with respect to the extent to which such means and processes are generalizable (common) across all species, the roles attributed to environmental factors including social beings in facilitating assimilations and accomodations, and the way the term modifiability is conceptualized.

Regarding Piaget's cognitive development theory of constructivism and its generalizability across all 'organisms' (Piaget's own word), the theory seems to be too simplistic in that the term 'organism' is used for animals, plants, and human beings interchangeably. In other words, Piaget considers innate differences in species' biological blueprints as the major source of differences observed in their abilities and the level of complexities in their behavior.

Also he ignores 'socialization' in general and 'instruction' in particular as two main environmental factors contributing to the individuals' learning and formation of more complex cognitive structures. He contends, instead, that human beings are different in their learning potentialities defined in terms of their IQ levels as well as their experience (Hergenhahn \& Olsen, 1993). Likewise, modifiability is conceptualized as a totally intrinsically-directed phenomenon which is determined and brought about by an organism's systematic stages of development available in different degrees of complexity in accordance with the nature of the organism.

Vygotsky, on the other hand, discards not only the generalizability which characterized Piaget's learning theory, but the passivity of the environmental factors in the process of scheme transitions (Wertsch, 1985). Rather, he conceived of socialization as the unique feature of human learning which marks the major difference between humans and other creatures. To him, for a development to take place, an individual's independent processing of the input, as Piaget views it, to successfully accommodate his mental structures (scheme), is neither sufficient nor reasonable (Murphy, 2008).

As for language learning, for example, Vygotsky $(1962,1978)$ believed that to account for the appropriateness of the linguistic input, given the limitations associated with learners (for both L1 and L2 learning) in processing the data as well as the peculiarities involved in the acquisition of a second language, consideration of socialization and instruction is of utmost significance and inevitable. Replacing the concept of scheme with that of the 'zone of proximal development', he contended that the difference between a learner's ability to perform a task alone and cooperatively with an instructor hinges on the fact that social interaction facilitates internalization of the input. In other words, although Vygotsky regarded second language learning as primarily a self-regulating process, he held that optimal learning does not occur unless a social interaction between the self and more experienced members of the community (a concomitance of self and socially-controlled instruction or mediation) takes place.

It follows that the concept of the zone of proximal development must be interpreted within a broader sociopsychological context, i.e. Vygotsky's theory of Social Development. According to this theory, social interaction plays a central role in the development of cognition - full cognitive development requires social interaction; thus, cognitive development succeeds social interaction opportunities. Social interaction is defined as the amount of adult guidance or peer collaboration upon which ZPD is arrived at. The extent to which development occurs in such a social interaction exceeds what can be attained alone (Lantolf, \& Poehner, 2004). Vygotsky laid the foundation of his theory on his experiments with children concluding that "Every function in the child's cultural development appears twice: first on the social level, and later, on the individual level; first, between people (interpsychological) and then inside the child (intrapsychological). This applies equally to voluntary attention, to logical memory, and to the formation of concepts. All the higher functions originate as actual relationships between individuals"(Vygotsky, 1978, p. 58).

In light of the above, upon reflection on the two positions held by Piaget and Vygotsky, one would hardly give credibility to Piaget's views of learning and development (e.g. intrapersonal nature of development, the presence of deriving force for equilibrium, self-directed concept acquisition which will ultimately lead to the development of a language system, etc.) as bearing the potential to account for a socially-directed, dialectic, instruction-based, assessment program the goal of which, among other classic goals, is to push learners forward onto a learning route and predict learners' potential performance level.

Meanwhile, as mentioned earlier, in some contexts, ongoing evaluation has been equated with DA. This misinterpretation is due to interpreting the term 'dynamic' as 'continual and ongoing' without considering the basic principles associated with the concept of DA. Obviously, conceptualizing modifiability as changes in the course of time due to instruction is different from the concept of modifiability based on a difference between independent performance 
and assisted performance at the time of assessment; only the latter captures the essence of a dynamic approach to assessing individual learners' potential as well as present learning abilities.

\section{DA: IS IT EQUAL TO FORMATIVE ASSESSMENT?}

The term formative assessment (also FA) typically refers to a number of measures and procedures adopted in classrooms at different time periods along a course of instruction with the objective of providing both the instructors and learners with feedback as to their success or failure as well as their strong and weak points (Bachman, 1990; Fulcher \& Davidson, 2007). At a more global level, FA is also thought of as yielding information regarding the effectiveness of the course material and the design of the curriculum itself. Garrison and Ehringhaus (2007) see FA as part of the instructional process:

"When incorporated into classroom practice, it provides the information needed to adjust teaching and learning while they are happening. In this sense, formative assessment informs both teachers and students about student understanding at a point when timely adjustments can be made. These adjustments help to ensure students achieve targeted standardsbased learning goals within a set time frame" (p. 1).

Likewise, d'Anglejan, Harley, and Shapson (1990) define FA as the process of gathering "information which will inform teachers and students about the degree of success of their respective efforts in the classroom. It allows teachers to diagnose students' strengths and weaknesses in relation to specific curricular objectives and thus guides them in organizing and structuring instructional material" (p. 107).

Meanwhile, however, some researchers like Leung and Mohan (2004) and Wood, Bruner, and Ross (1976) have conceived of DA as a particular type of FA and have, as such, interpreted it as standing in stark contrast to static assessments. Such a conceptualization, however, flies in face of reality as the two concepts are not indeed synonymous and hence cannot be used interchangeably. They are therefore critically reviewed in the following lines.

DA as a special type of FA in disguise is a misinterpretation of the concept. To be sure, they have in common the practice of assisting the learners in completing the required tasks; they do differ, however, with respect to the purposes for which they provide such assistance and the means to those ends. While DA is grounded in a well-established theory of development, i.e. ZPD, and is as such systematic in its practices, formative assessment is not based on any theory of development or learning. Moreover, in the former the negotiation and renegotiation of mediated assessment is, in addition to short-term goals (threshold development or modifiability), aimed at a long-term objective - prediction of learners' conscious awareness and control of a particular skill or content area in future on the basis of their present ability to transfer mediated performance to other unmediated contexts of use. However, in the latter the mediated performance merely plays a scaffolding (supporting) role in the completion of here-and-now tasks even when learners are required to reason their way through the answers - where modifiability is not a goal- and at its best is more aimed at providing feedback into teaching than at learners' future development in that the learners' strengths and weaknesses are taken into account so far as they feed back into teaching and reorganization of the instructional procedures and material. It follows that in purely FA-based programs, development, if any, might be achieved but it is for the most part unintended and incidental. It relies on the instructors' intuitions as to the type and rate of assistance which vary not only across instructors but even within the same instructor over time in an unsystematic hit-or-miss fashion. This unsystematicity may lead to either overestimation or underestimation of the learners' abilities and progress which would, in turn, result in "inappropriate instruction or no instruction at all when it is in fact required" (Rea-Dickins \& Gardner, 2000, p. 238). It goes without saying, however, that an FA design is an essential part of any DA program since merely describing a learner's development as poor will not reveal the reasons for their poor performance. Nor does it provide recommendations as to efficient remedial measures aimed at enhancing their rate and quality of development.

Moreover, assessment in DA is not solely formative; it is also in part summative. The focus on either one or the other depends on a multitude of purposes and goals which underlie the express unitary objective of development in the future. While formative and summative assessments have been so far considered as mutually exclusive forms of evaluation due to the assumptions underlying the reliability and validity of test scores, DA draws on both insisting on the inseparability of assessment and instruction which together (according to DA) form learner development. In fact DA has the potential to unveil facts about learners' developmental status that other standardized assessments would otherwise fail to reveal. This failure then could lead to an underestimated evaluation of a learner's development (as poor) while the results of DA do not support such a position or it could simply overestimate the rate of a learner's development where, for example, standardized assessments do not indicate those delayed developments that DA most probably does. This fact has not gone unnoticed by Poehner and Lantolf (2005): "DA minimizes the risk of an erroneous evaluation, by definition. It provides mediation that is constantly adjusted and attuned to the learner's or group's responsiveness to mediation. At the same time, it promotes the very development it seeks to assess in the first place" ( p. 252).

It follows that while in classic assessments the only feedback the examinees receive is a report on their scores, dynamic assessments are characterized by the examiners' attempts to modify the examinee's performance during the assessment employing both cognitive and affective feedbacks. This characteristic then is one more demarcation line between DAs and other non-DA types of assessment. 
Dynamic assessment was defined above as a complex of procedures around the task of modifying learners' performances via tutor-examiners' assistance in an effort to yield information as to the potential development of the testees in future.

If the three components introduced by Freustein (intentionality, reciprocity, and transcendence) are incorporated into the definition, then, it yields the following: the complex of systematic but reciprocally determined procedures around the task of modifying learners' performances via tutor-examiners' assistance in an effort to yield information as to the potential development of the testees in future. This potential development is a direct function of the degree of modification, its stability over time and across tasks, and the amount of mediation required by a learner to change their performance and transcend that mediated performance over time and across tasks.

Operationally, then, learners' potential development could be assessed through recording the correctness of response data (response given to mediations), both within and beyond the mediation sessions, and dividing it by the number of aids required by learners to achieve certain levels of ability (change).

\section{SUMMARY AND CONCLUSION}

While traditional classroom instructions were characterized by rigidly closed syllabi where the routes to language mastery were systematically organized into learning sequences based on the difficulty level of the structures or tasks, and the degree of the learners' success in proceeding through such hierarchies was determined by evaluating their independent performance on achievement tests, the learning route in alternative DA programs is not sequential and invariant and its scope and content is determined in an unanticipated, yet purposeful, fashion via instructor - learner interactions and negotiations. This interaction, however, is two-fold: it is targeted at both instruction and evaluation with the express objective of determining learners' zone of potential (proximal) development. The key factor here is to bring about changes (modifications) by way of instruction and then assess the degree of modifiability in the learners.

Despite this simplicity in definition, dynamic assessment has been realized in distinct and even conflicting ways with, in some extreme cases, little if any correspondence to the original assumptions or principles. Four such interpretations were examined here against the basic assumptions of DA: false DAs (ongoing evaluations and formative assessments wrongly interpreted as DA), interventionist DA, and interactionist DA. Of these four designs, only one (the interactionist design) seems to have fully adhered to the basic tenets and theoretical assumptions specified in a true DA program. Other three fail to meet the requirements of a fully-fledged dynamic assessment program.

To conclude, we cautioned against assuming that dynamic assessment refers solely to either of the three designs explicated above. More specifically, we caution against developing any other false DAs which might emerge as a result of ignoring or overlooking one or a number of features and characteristics associated with a true DA program; A fact which, if taken into account, will give rise to well-designed and adequately-defined dynamic assessment programs.

\section{REFERENCES}

[1] Bachman, L.F. (1990). Fundamental considerations in language testing. Oxford: Oxford University Press.

[2] Brown, D. (2007). Principles of language learning and teaching. New York: Pearson Education.

[3] Budoff, M. (1987). Measures for assessing learning potential. In C.S. Lidz (eds.), Dynamic assessment: An interactive approach to evaluating learning potential, New York: Guilford, 173-195.

[4] d'Anglejan, A., Harley, B. and Shapson, S. (1990). Student evaluation in a multidimensional core French curriculum. Canadian Modern Language Review, 47.1, 106 -124.

[5] Dorfler, T., Golke, S., and Artlet, C. (2009). Dynamic assessment and its potential for the assessment of reading competence. Studies in Educational Evaluation, 35, 77- 82.

[6] Feuerstein, R., Rand, Y. and Hoffman, M.B. (1979). The dynamic assessment of retarded performers: the learning potential assessment device, theory, instruments, and techniques. Baltimore, MD: University Park Press.

[7] Feuerstein, R., Rand, Y., Hoffman, M.B. and Miller, R. (1980). Instrumental enrichment. Baltimore, MD: University Park Press

[8] Feuerstein, R., Rand, Y. and Rynders, J.E. (1988). Don't accept me as I am. Helping retarded performers excel. New York: Plenum.

[9] Feuerstein, R., Falik, L., Rand, Y. and Feuerstein R.S. (2003). Dynamic assessment of cognitive modifiability. Jerusalem: ICELP Press.

[10] Fulcher, G. \& Davidson, F. (2007). Language testing and assessment. An advanced resource book. London: Routledge.

[11] Garrison, C., and Ehringhaus, M. (2007).Formative and summative assessments in the classroom. http://www.nmsa.org/publications WebExclusive/Assessment/tabid/1120/Default.aspx

[12] Hergenhahn, B. and Olsen, M.H. (1993). An introduction to theories of learning. Prentice Hall International, Inc.

[13] Kozulin, A. and Garb, E. (2002). Dynamic assessment of EFL text comprehension of at-risk students. School Psychology International, 23, 112-27.

[14] Lantolf, J.P. and Poehner, M.E (2004). Dynamic assessment of L2 development: bringing the past into the future. Journal of Applied Linguistics, 1, 49-72.

[15] Leung, C. and Mohan, B (2004). Teacher formative assessment and talk in classroom contexts - assessment as discourse and assessment of discourse. Language Testing, 21, 335-59.

[16] Lidz, C.S. (1991). Practitioner's guide to dynamic assessment. New York: Guilford

[17] Lidz, C. and Elliott, J. (eds.) (2000). Dynamic assessment: prevailing models and applications (Advances in cognition and educational practice), Vol. 6. Elsevier Science Inc. 
[18] Lussier, C. M. and Swanson, H. L. (2005). Dynamic assessment: A selective synthesis of the experimental literature. In G. M. van der Aalsvoort, W. C. M. Resting, \& A. J. J. M. Ruijssenaars (eds.). Learning potential assessment and cognitive training: Actual research and perspectives in theory building and methodology, New York: Elsevier, 65-87.

[19] Minick, N. (1987). Implications of Vygotsky's theories for dynamic assessment. In Lidz, C.S. (ed.), Dynamic assessment: an interactive approach to evaluating learning potential, New York: The Guilford Press, 116-40.

[20] Murphy, R. (2008). Dynamic assessment precursors: Soviet ideology and Vygotsky. The Irish Journal of Psychology, 29. 3 , 193-233.

[21] Newman, D., Griffin, P. and Cole, M. (1989). The construction zone: working for cognitive change in school. Cambridge: Cambridge University Press.

[22] Poehner, M. E. and Lantolf, J. P. (2005). Dynamic assessment in the language classroom. Language Teaching Research, 9. 3 , $233-65$.

[23] Poehner, M.E. (2008) Dynamic assessment: A Vygotskian approach to understanding and promoting L2 development. US: Springer.

[24] Rea-Dickins and Gardner (2000). Snares and silver bullets: disentangling the construct of formative assessment. Language Testing, 17, 215-43.

[25] Sternberg, R.J. and Grigorenko, E.L. (2002). Dynamic testing: the nature and measurement of learning potential. Cambridge: Cambridge University Press.

[26] Vygotsky, L.S. (1962). Thought and language. Cambridge, MA: MIT Press.

[27] Vygotsky, L.S. (1978). Mind in society. Cambridge, MA: Harvard University Press.

[28] Wertsch, J.V. (1985). Vygotsky and the social formation of mind. Cambridge, MA: Harvard University Press.

[29] Wood, D., Bruner, J. and Ross, G. (1976). The role of tutoring in problem solving. Journal of Child Psychology and Psychiatry, $17,89-100$

[30] Yunian, X.. \& Ness, V. (1999). Ongoing evaluation: The role of teachers and learners. Forum. 37. 4, 16-21.

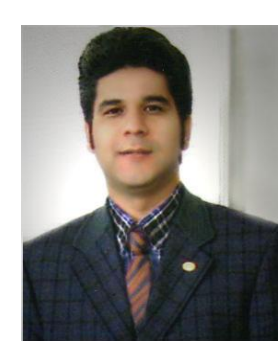

Mohammad Bavali (b. 1979, Abadan, Iran) is a Ph.D. candidate of TEFL at the IAU Science and Research, Shiraz Branch, where he is also a faculty member at the School of English Language Teaching and Translation. His research interests include theories of testing and assessment, methods of research in L2, foreign language learning and teaching, CDA, critical pedagogy, and translation studies.

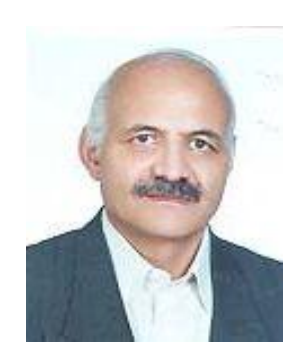

Mortaza Yamini (b. 1949, Zanjan, Iran) is an assistant professor who taught for 35 years at Shiraz University before he retired a few years ago. He is still pursuing his teaching profession, offering some graduate courses at Shiraz University and the Islamic Azad University, Shiraz Branch. He has also published a good number of articles and books on second language learning and teaching, testing and other areas of applied linguistics in local and international journals. Dr Yamini is also an active member of the Center of Excellence in L2 Reading and Writing, Shiraz University.

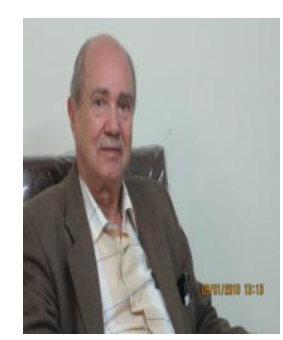

Firooz Sadighi (b. 1939, Bavanat, Iran) is a professor of English language and linguistics at Shiraz University and Islamic Azad University. He received his Ph.D. from the University of Illinois, USA in 1982. He has taught courses such as 'Psycholinguistics', 'First Language Acquisition', 'Second Language Acquisition' and 'Syntactic Argumentation' in the Ph.D program in TEFL. Likewise, he has taught several courses in linguistics and its related areas to M.A. students in TEFL and General Linguistics in both universities. He has published numerous articles (locally and internationally) and books. He has also supervised several M.A theses and Ph.D dissertations at the Department of Foreign Languages and Linguistics and Azad University. His research areas are 'foreign/second language learning and teaching', 'linguistics including syntax, semantics, and phonology' and 'syntactic argumentation'. 